\title{
Sugarcane Water Productivity Assessments in the São Paulo state, Brazil
}

\author{
Antônio H. de C. Teixeira ${ }^{* 1}$, Janice F. Leivas ${ }^{2}$, Carlos C. Ronquim ${ }^{3}$, Daniel de C. Victoria ${ }^{4}$ \\ 1,2,3Embrapa Satellite Monitoring; ${ }^{4}$ Embrapa Agriculture Informatics Campinas, São Paulo, Brazil \\ "1heriberto.teixeira@embrapa.br; 2janice.leivas@embrapa.br; ${ }^{3}$ carlos.ronquim@embrapa.br; \\ ${ }^{4}$ daniel.victoria@embrapa.br
}

\begin{abstract}
São Paulo state, Brazil, has been highlighted by the sugarcane crop expansion. The actual scenario of climate and land use changes, bring attention for the large-scale water productivity (WP) analyses. MODIS images were used together with gridded weather data for these analyses. A generalized sugarcane growing cycle inside a crop land mask, from September 2011 to October 2012, was considered in the main growing regions of the state. Actual evapotranspiration (ET) is quantified by the SAFER (Simple Algorithm for Evapotranspiration Retrieving) algorithm, the biomass production (BIO) by the RUE (Radiation Use Efficiency) Monteith's model and WP is considered as the ratio of BIO to ET. During the four generalized sugarcane crop phases, the mean ET values ranged from 0.6 to $4.0 \mathrm{~mm}$ day $^{-1}$; BIO rates were between 20 and $200 \mathrm{~kg} \mathrm{ha}^{-1}$ day $^{-1}$, resulting in WP ranging from 2.8 to $6.0 \mathrm{~kg} \mathrm{~m}^{-3}$. Soil moisture indicators are applied, indicating benefits from supplementary irrigation during the grand growth phase, wherever there is water availability for this practice. The quantification of the large-scale water variables may subsidize the rational water resources management under the sugarcane expansion and water scarcity scenarios.
\end{abstract}

Keywords

Remote Sensing; Evapotranspiration; Biomass Production; Water Resources; Bioenergy Crop

\section{Introduction}

In Brazil, sugarcane (Saccharum officinarum) crop has increased, for both sugar and alcohol production, but also with the perspective of generating renewable energy [1]. In the São Paulo state, besides climate alterations, land use changes have been taking place, because of the expansion of these activities in several regions with climatic aptitude.

The negative effects, in areas before occupied by natural vegetation, citrus, grains, and coffee [2] could be more harmful when comparing with those from the fossil fuel exploration, regarding greenhouse gas emissions [3].

On one hand, aiming bioenergy production, a crop should be fast growing and high yielding with its energy output exceeding fossil fuel energy input. In terms of satisfying these criteria, sugarcane is currently the most promising energy crop [4]. On the other hand, its cultivation increases regional water demands [5] and there are many concerns about the impacts on the carbon cycle [6]; further affecting the large-scale energy, water and carbon balances [7].

Increasing large-scale evapotranspiration rates because of the sugarcane crop expansion has been reported [8]. Ethanol production can also affect the water quality [9]. Under these dynamic situations, the use of tools for quantifying actual evapotranspiration (ET) and biomass production (BIO) on a large scale is relevant for supporting policy plannings and decision makings about the water resources.

In Brazil, sugarcane ET has been determined by point measurements. Silva et al. [10] used the Bowen method system inside a commercial irrigated farm in a semi-arid region. Cabral et al. [11], in the São Paulo state, carried out eddy covariance measurements under rainfed conditions. However, these point studies provide specific site values and are not suitable for water productivity (WP) large-scale analyses.

$\mathrm{BIO}$ is a key indicator for any ecosystem [12], and its values are highly variable in both space and time. In waterlimited environments, the challenge is the BIO improvements through optimized management practices [13] [14] [15] [16]. De Silva and De Costa [13] measured BIO in irrigated and rainfed sugarcane, reporting higher values 
under irrigation conditions. BIO field measurements were realized under under rainfed conditions by Cabral et al. [17] in the Southern Brazil.

The difficulties of measuring and analyzing the large-scale energy, carbon and water balances with only with field measurements highlighted the importance of coupling remote sensing and weather data. These tools have been successfully used in energy crops under different climatic conditions [2] [14] [16] [18] [19].

The SAFER (Simple Algorithm for Evapotranspiration Retrieving) algorithm is applied in the current research to estimate ET on large-scale. It was developed and validated in Brazil based on simultaneous field data from four flux towers and Landsat images under strongly thermohydrological contrasting conditions [20] [21].

For large-scale BIO quantification, the radiation use efficiency (RUE) concept proposed by Monteith [22], based on the solar radiation interception, is used with satellite data. Although uncertainties arising in connection with RUE values in sugarcane crop, due to their spatiotemporal variations [23], moisture conditions [13] and cultivars [24], the model accuracy has been considered acceptable for large-scale applications with satellite data.

In France, field measurements were coupled with high-resolution FORMOSAT satellite images in irrigated maize and rainfed sunflower, where the authors attributed the main spatial BIO differences to precipitation conditions during the second crop [18]. BIO was estimated from MODIS images in Guandong, China, to evaluate the feasibility of setting up new biomass power plants and to optimize the locations of plants [25]. In Brazil, large-scale BIO estimations were done with MODIS images in maize [26] and Landsat images in sugarcane crop [27].

Despite these previous studies on energy crops, research is needed to further evaluate the combined ET and BIO models in sugarcane ecosystems, especially for operational monitoring. With a cropland mask, the SAFER algorithm to obtain ET and the RUE Monteith's model to estimate BIO are used in the sugarcane growing regions inside the São Paulo state, Brazil. Soil moisture indicators and WP in terms of the ratio of BIO to ET are analyzed by using MODIS images and weather data. The results may subsidize policies for a rational sugarcane water management. This is a very important issue under the actual scenario of water competitions with other sectors in the Brazilian Southeast, as consequences of both climate and land use changes.

\section{Material and Methods}

\section{Study Region and Data Set}

Fig. 1 shows the location of the sugarcane-growing regions, cropland mask and the weather stations in the São Paulo state, Brazil.

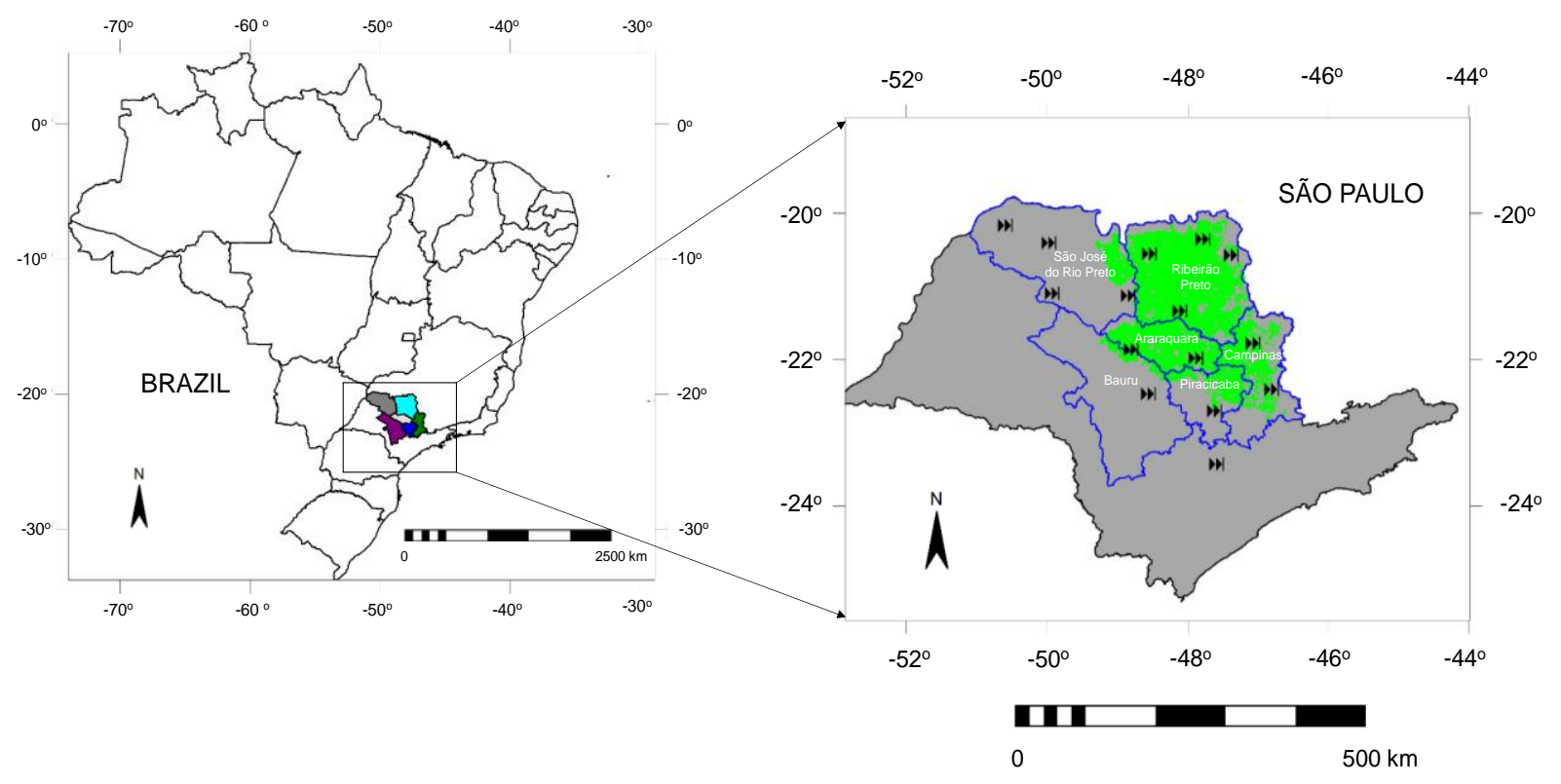

FIG. 1 LOCATION OF THE SUGAR CANE- GROWING REGIONS, THE CROP LAND MASK (GREEN AREA), AND THE WEATHER STATIONS (BLACK ARROWS) 
The sugarcane-growing regions, present two well-defined seasons, one rainy and hotter and the other one dry and colder. According to Cabral et al. [17], the long-term maximum precipitation occurs in December $\left(274 \pm 97 \mathrm{~mm} \mathrm{month}^{-1}\right)$ and the minimum one is between July and August $\left(27 \pm 34 \mathrm{~mm} \mathrm{month}^{-1}\right)$; the annual value is $1517 \pm 274 \mathrm{~mm} \mathrm{yr}^{-1}$. The mean air temperatures in January and July are respectively $24^{\circ} \mathrm{C}$ and $19{ }^{\circ} \mathrm{C}$; the annual average is $22^{\circ} \mathrm{C}$.

MODIS images during the generalized sugarcane growing cycle (GC) from September 2011 to October 2012, inside the cropland mask, were used, along with the 15 agrometeorological stations from the National Meteorological Institute - INMET. Global solar radiation $\left(R_{\mathrm{G}}\right)$, air temperature $\left(\mathrm{T}_{\mathrm{a}}\right)$, relative humidity $(\mathrm{RH})$ and wind speed $(\mathrm{u})$ were taken to calculate the reference evapotranspiration (ETo) by the Penman-Monteith method [28]. RG, Ta and $\mathrm{ET}_{0}$ were averaged for over the 16-day composing periods from the MODIS MOD13Q1 reflectance products (spatial resolution of $250 \mathrm{~m}$ ) and interpolated by using the moving average method creating grids with the same spatial resolution as that for the satellite images.

This weather upscaling process was done to have representative grids of the average conditions for the same timescale of the MODIS satellite composing images. Similar process was done by Cleugh et al. [29], who used the Penman-Monteith equation to monitor large-scale ET in Australia.

The surface temperature $(\mathrm{Ts})$ product was not used because with a lower spatial resolution $(1 \mathrm{~km})$, there was too much cloud contamination along the year in the cropland mask. Instead, Ts was retrieved by residue in the radiation balance. In addition, Cleugh et al. [29] pointed out that the use of instantaneous measurements of the radiometric Ts to calculate time-averaged fluxes lead to errors. They emphasized uncertainties in models which use the MODIS 8-day products that is a composite of once-daily overpass at $\sim 10: 30 \mathrm{~h}$ local time.

\section{Modelling Steps}

Fig. 2 shows the flowchart of the steps for modeling sugarcane water productivity components throughout SAFER and RUE applications to MODIS images without the thermal bands.

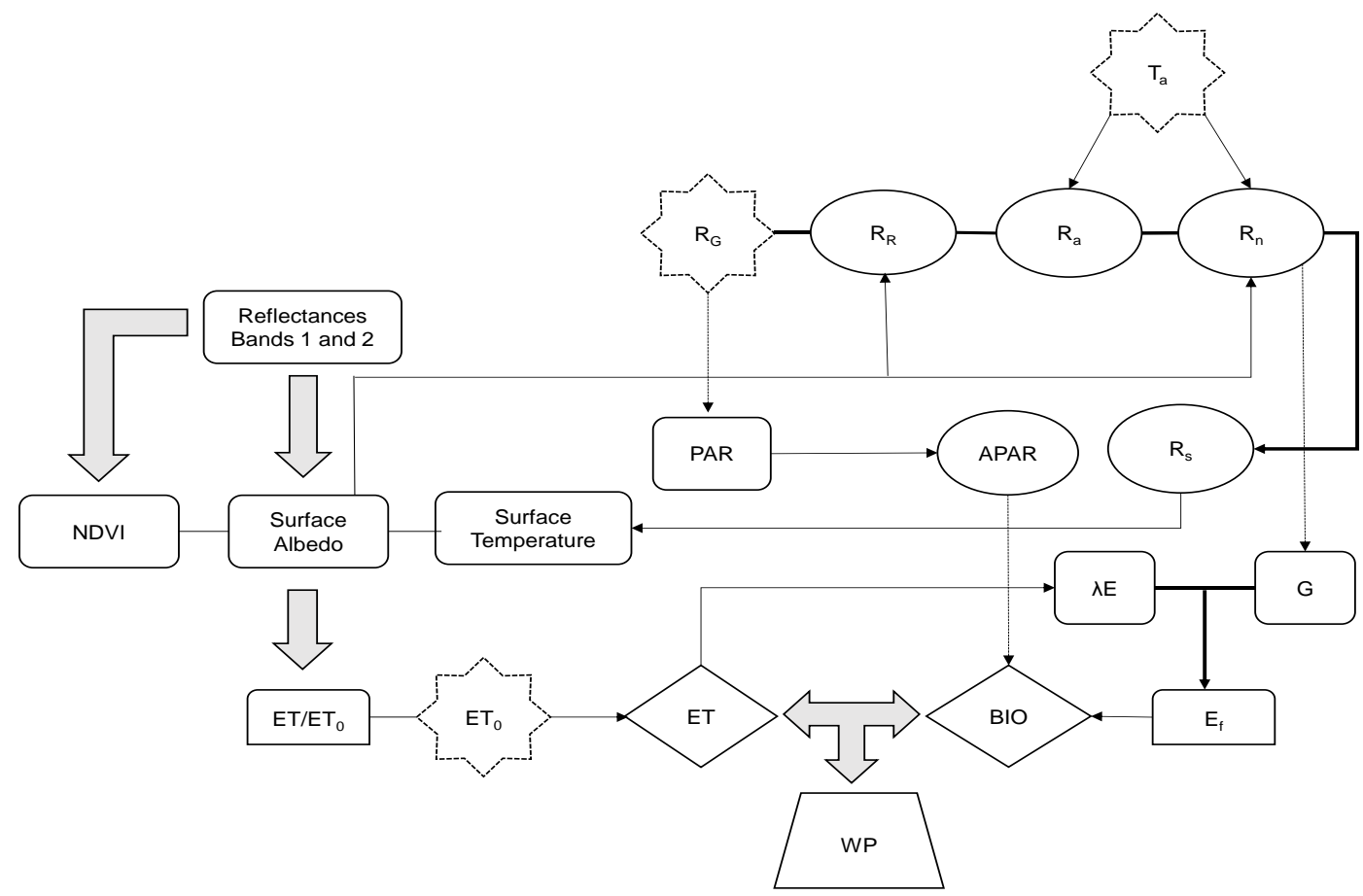

FIG. 2 FLOW-CHART FOR THE SUGARCANE WATER PRODUCTIVITY

SAFER model was elaborated and validated in Brazil with Landsat images [21], when it was called PM2. Later it was also calibrated and validated with MODIS images in the same original modelling region [15]. Field data for these validations involved irrigated crops and natural vegetation (Caatinga) from 2001 to 2007, being described in details in Teixeira et al. [20]. 
Accordingly to Fig. 2, the reflectances for the bands $1\left(\alpha_{1}\right)$ and $2\left(\alpha_{2}\right)$ were extracted from the MOD13Q1 product. This product provided cloud-free temporal composed images, at 16-day periods, throughout the generalized sugarcane GC from September 2011 to October 2012.

For the surface albedo $\left(\alpha_{0}\right)$ calculation, the following equation was applied [30]:

$$
\alpha_{0}=a+b \alpha_{1}+c \alpha_{2}
$$

where $\mathrm{a}, \mathrm{b}$ and $\mathrm{c}$ are regression coefficients, considered as 0.08, 0.41, 0.14, obtained under different Brazilian vegetation types and thermohydrological conditions [15].

The Normalized Difference Vegetation Index (NDVI) is an indicator related to the land cover and moisture conditions obtained from the MODIS images as follows:

$$
N D V I=\frac{\alpha_{2}-\alpha_{1}}{\alpha_{2}+\alpha_{1}}
$$

where $\alpha_{2}$ and $\alpha_{1}$ represent the reflectances over the ranges of wavelengths in the near infrared (NIR) and red (RED) regions of the solar spectrum, respectively.

$\mathrm{R}_{\mathrm{n}}$ was estimated through the Slob equation [16] [26]:

$$
R_{n}=\left(1-\alpha_{0}\right) R_{G}-a_{L} \tau
$$

where the regression coefficient aL was spatially distributed through its relationship with $T_{a}[20]$ :

$$
a_{L}=d T_{a}-e
$$

with $\mathrm{d}$ and e being the regression coefficients 6.99 and 39.93. A constant value aL $=110$ was applied by Bastiaanssen et al. [31] without considering thermal spatial differences.

The large-scale reflected solar radiation $\left(R_{R}\right)$ was calculated as the product of $R_{G}$ by $\alpha_{0}[16]$ :

$$
R_{R}=\alpha_{0} R_{G}
$$

The long-wave atmospheric radiation $\left(\mathrm{R}_{\mathrm{a}}\right)$ was obtained by applying the Stefan-Boltzmann low:

$$
R_{a}=\sigma \varepsilon_{a} T_{a}^{4}
$$

where $\sigma$ is the Stefan-Boltzmann constant $\left(5.67 \times 10^{-8} \mathrm{~W} \mathrm{~m}^{-2} \mathrm{~K}^{-4}\right)$ and the atmospheric emissivity $\left(\varepsilon_{a}\right)$ was calculated as follows:

$$
\varepsilon_{a}=a_{a}(-\ln \tau)^{b_{a}}
$$

and $\tau$ is the short-wave atmospheric transmissivity calculated by the ratio of $R_{G}$ to the incident solar radiation at the top of the atmosphere; $a_{a}$ and $b_{a}$ are the regression coefficients 0.94 and 0.10 , respectively [16].

The regression coefficients of Eq. 7 are in between those obtained for Idaho $\left(a_{a}=0.85\right.$ and $b_{a}=0.09$; [32]) and for Egypt $\left(a_{a}=1.08\right.$ and $b_{a}=0.26$; [31]). However, even with these small differences under contrasting environmental conditions, estimate errors for these emissivities in the Brazilian sugarcane ecosystem are self-compensating when accounting for the upward and downward radiation balance components.

The surface emitted long-wave radiation $\left(R_{s}\right)$ was acquired as residue in the radiation balance equation:

$$
R_{s}=R_{G}-R_{R}+R_{a}-R_{n}
$$

and Ts retrieved [16] [19]:

$$
T_{S}=\sqrt[4]{\frac{R_{S}}{\varepsilon_{S} \sigma}}
$$


The surface emissivity (es) was calculated as follows ([16] [19]):

$$
\varepsilon_{S}=a_{S} \ln N D V I+b_{S}
$$

where as and bs are regression coefficients 0.06 and 1.00 , respectively.

The original coefficients of Eq. 10 are as $=0.047$ and $b s=1.009$ [31], being slightly different from those for Brazil. However, even with these small differences under contrasting environmental conditions, estimate errors for these emissivities in São Paulo, Brazil, are also self-cancelled in the accounting of the upward and downward radiation balance components.

With the SAFER algorithm, the ratio of actual (ET) to the reference (ETo) evapotranspiration $\left(E T_{r}\right)$ was modelled at the satellite overpass time [21]:

$$
E T_{r}=\left\{\exp \left[a_{s f}+b_{s f}\left(\frac{T_{S}}{\alpha_{0} N D V I}\right)\right]\right\} \frac{E T_{0}-G C}{5}
$$

where asf and $b_{\text {sf }}$ are the regression coefficients 1.8 and -0.008 , respectively. The correction factor (ET0_Gc/5) was applied for atmospheric demand calibration, being ETo_Gc the daily ETo grid for the sugarcane GC, and $5 \mathrm{~mm} \mathrm{~d}^{-1}$ is the ETo daily average for the same period during the original modeling conditions [19].

The daily grids of ETo from the agrometeorological station (black arrows in Fig. 1) were multiplied by the images resulted from Eq. 11, giving the large-scale daily ET pixel values [16] [19] [21]:

$$
E T=E T_{r} E T_{0}
$$

For the soil heat flux $(\mathrm{G})$, the equation derived by Teixeira [21] was applied:

$$
\frac{G}{R_{n}}=a_{G} \exp \left(b_{G} \alpha_{0}\right)
$$

A climatic moisture indicator for the sugarcane conditions was also considered [19]:

$$
W I=P / E T
$$

Eq. 14 enables the characterization of the climatic water component to take into account the input and output of natural water from and to the crop, indicating the potential moisture availability to the sugarcane root zones.

BIO was quantified as:

$B I O=\varepsilon_{\max } E_{f} A P A R \quad 0.864$

where $\varepsilon_{\max }$ is the maximum light use efficiency, which considered the average value of $2.14 \mathrm{~g} \mathrm{MJ}^{-1}$ for sugarcane [24], APAR is the fraction of absorbed photosynthetically active radiation, and 0.864 is a conversion factor [15].

APAR can be directly approximated from the Photosynthetically Active radiation (PAR), which in turn was considered as a fraction of $R_{G}[15]$ [33]:

$$
A P A R=f_{P A R} P A R
$$

The factor fPAR was estimated from the NDVI values:

$$
f_{P A R}=a_{p} N D V I+b_{p}
$$

where the coefficients $a_{p}$ and $b_{p}$ of 1.257 and -0.161 , respectively, reported for a mixture of arable crop types [33] were considered.

The water productivity (WP) based on evapotranspiration [15] [26] was considered as:

$$
W P=B I O / E T
$$




\section{Results and Discussion}

\section{Weather Conditions and Sugarcane Phases}

Fig. 3 presents the trends for the totals of precipitation $(\mathrm{P})$ and $\mathrm{ET}_{0}$ together with that for the RG daily averages.

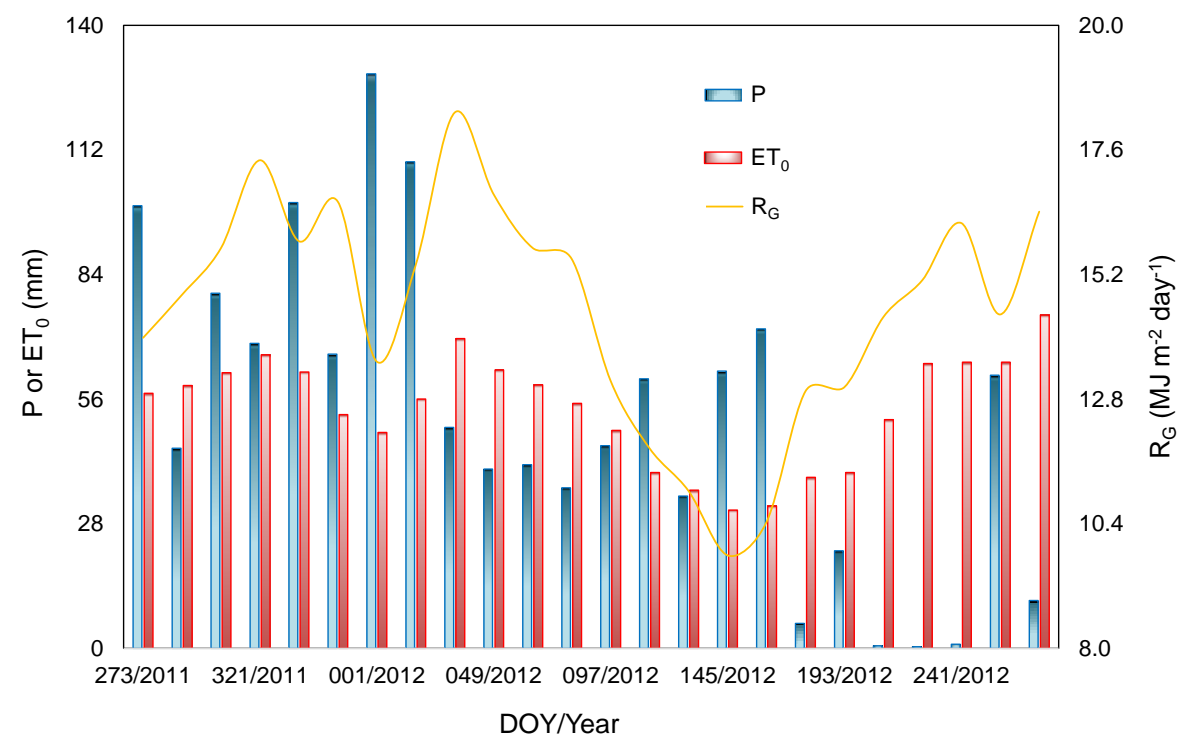

FIG. 3 SEASONAL VARIATIONS OF THE AVERAGE VALUES FOR GLOBAL SOLAR RADIATION (RG); AND TOTALS OF PRECIPITATION (P) AND REFERENCE EVAPOTRANSPIRATION (ETo)

The values depicted in Fig. 3 are for each the MODIS 16-day periods, inside the generalized sugarcane GC, in the growing regions of the São Paulo state, Brazil. The weather data resulted from the interpolation processes in the cropland mask, from September 2011 to October 2012 in terms of Day of the Year (DOY)

Following Silva et al. [10], the sugarcane phases may be divided into four: Phase 1 - Germination and Establishment; Phase 2 - Tillering; Phase 3 - Grand Growth; and Phase 4 - Ripening and Maturation.

Phase 1 denotes activation and subsequent sprouting of the vegetative bud. It is influenced by soil moisture, soil temperature and soil aeration. Phase 2 starts from around 40 days after the GC initiation and may last up to 120 days. Variety, $R_{G}, T_{a}$, soil moisture and fertilization influence this phase. Phase 3 starts from 120 days after the GC starting and lasting up to 270 days in a 12-month crop. High both, soil moisture and RG levels, favor better cane elongation during this phase. Phase 4 in a 12-month sugarcane crop lasts for about three months starting from 270360 days after the GC initiation. High Rg levels and low soil moisture conditions are favorable during this phase. This last phase is characterized by slower growth activity [34].

From Fig. 3, the highest values of both RG and ET, were observed between the Phases 2 and 3, from November (DOY 321/2011) to early April (DOY 097/2012). In that period, mean RG reached to rates above $20 \mathrm{MJ} \mathrm{m}^{-2}$ day-1, $^{-1}$ promoting ETo over $4.5 \mathrm{~mm}^{\text {day-1}}{ }^{-1}$, being favorable for BIO.

Rainfalls of $1240 \mathrm{~mm}$ in total for the entire generalized GC, although being below the long-term value of the study area, were well distributed along the crop phases. Cabral et al. [17] reported a 13\% of BIO reduction in relation to the regional average in São Paulo state, Brazil, as a consequence of the lower natural water availability observed during the initial 120 days of cane re-growth. However, in the current research, a short drier period was verified from late June to the second half of August (DOY 177 to 257 of 2012), corresponding to periods inside Phase 3, which should have caused some crop water deficit, when sugarcane water requirements are high.

For rainfed sugarcane crop, a GC precipitation between 1100 and $1500 \mathrm{~mm}$ with good distribution is considered adequate. During the active growth phases, water deficit could reduce the leaf area, affecting the number of tillers and leaves per stalk [35]. However, during Phase 4, rains are not desirable because they lead to poor juice quality [34]. The decline in rainfall at the end of the GC was then favorable for sugarcane WP. 


\section{Actual Evapotranspiration}

Fig. 4 shows the spatial distribution of the sugarcane ET daily averages, for the 16-day period MODIS images, from September 2011 to October 2012 in the growing areas of the São Paulo state, Brazil.

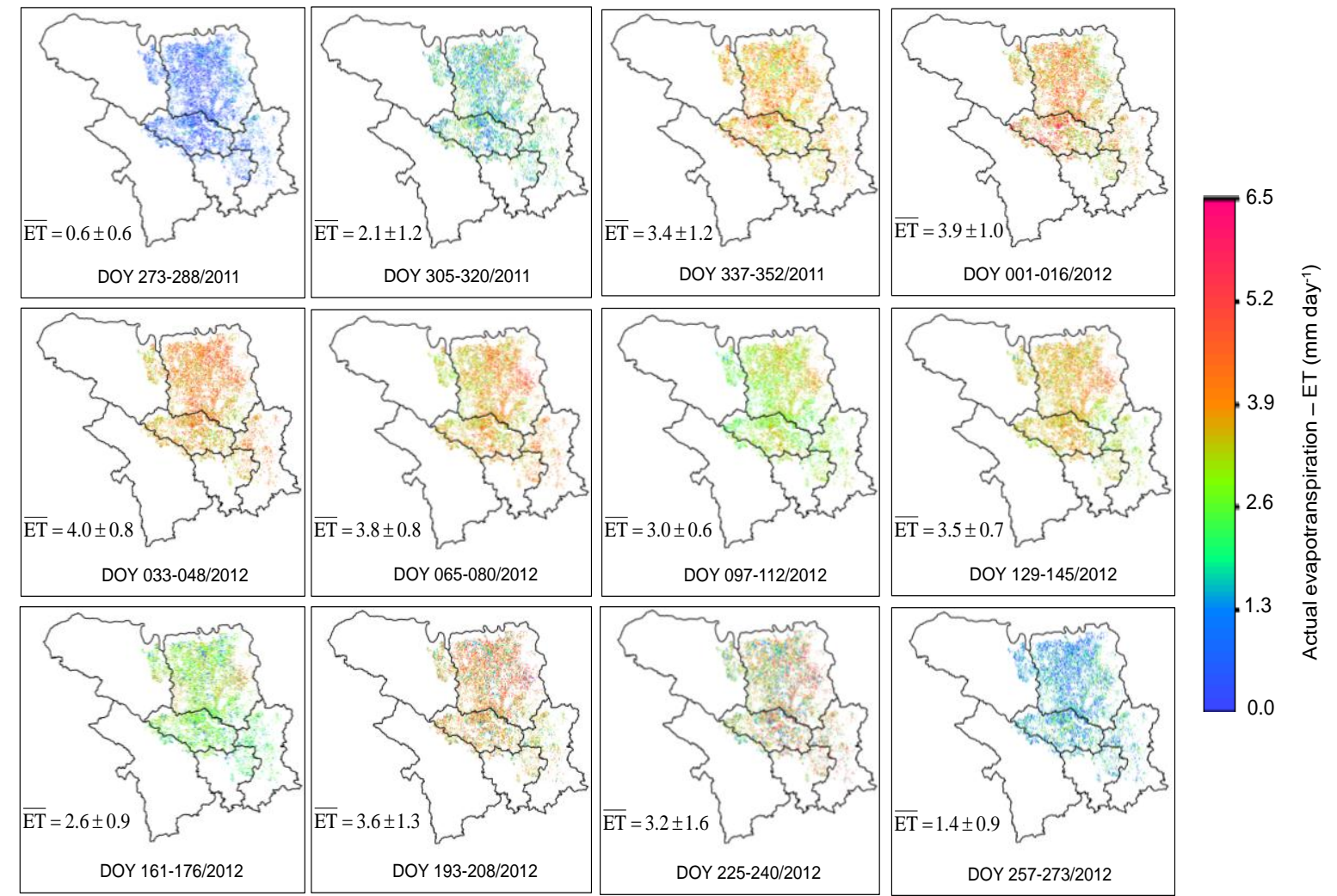

FIG. 4 SPATIAL DISTRIBUTION FOR THE 16-DAY AVERAGE VALUES OF THE SUGARCANE EVAPOTRANSPIRATION (ET)

The spatial and temporal ET variations are evident inside the cropland mask, along the generalized rainfed sugarcane GC from September 2011 to October 2012. The strong contrast is noticed mainly when looking for the pixels in the images of DOY 273-288/2011 and 033-048/2012. The maximum values were verified under high both rainfall amount and atmospheric demand (see Fig. 3 and 4), in early February 2012, when the daily average for ET was $4.0 \mathrm{~mm}$ day $^{-1}$ (DOY 033-048/2012), inside the Phase 3. The lowest ET rates, below $1.5 \mathrm{~mm}^{-1} \mathrm{y}^{-1}$, took place in the Phase 1, from DOY 273 to 305 of 2011 and at the end of Phase 4, from the second half of September (DOY 257/2012) to the first half of October (DOY 281/2012).

In relation to the ET spatial variations, the lowest standard deviation (SD) values $(0.6 \mathrm{~mm}$ day-1) happened also at the start of the generalized GC (Phase 1), while the highest ones $\left(1.6 \mathrm{~mm} \mathrm{day}^{-1}\right)$ were in Phase 4 , at the end of the rainy season (see Figs. 3 and 4).

In the mixture of sugarcane plants, inside the cropland mask, average ET ranged from 0.6 to $4.0 \mathrm{~mm}^{-1} \mathrm{y}^{-1}$, with a mean GC value of $3.0 \mathrm{~mm}^{\text {day }}{ }^{-1}$. The total ET for a GC of 400 days was $1180 \mathrm{~mm}$. The ET daily values were above those reported by Eksteen et al. [36], who found rates between 1.6 and $2.9 \mathrm{~mm}^{-1 a y}{ }^{-1}$, involving different sugarcane varieties and soil moisture conditions. However, a previous study with sugarcane, under irrigation conditions, in Everglades, Florida (USA), by Omary and Izuno [37], resulted in minimum daily rates of 0.7 to $1.5 \mathrm{~mm}^{-1 a y}{ }^{-1}$, and maximums of 4.5 to $4.6 \mathrm{~mm}^{\text {day-1, }}{ }^{-1}$ with a total GC of $1060 \mathrm{~mm}$. The similar values of the current study with that one in Florida provide confidence for the application of the SAFER algorithm to MODIS images and without the thermal band.

\section{Soil Moisture Indicators}

Fig. 5 shows the ETr and WI average trends, throughout the generalized sugarcane GC, in the growing regions of the São Paulo state, Brazil, in terms of Day of the Year (DOY). 


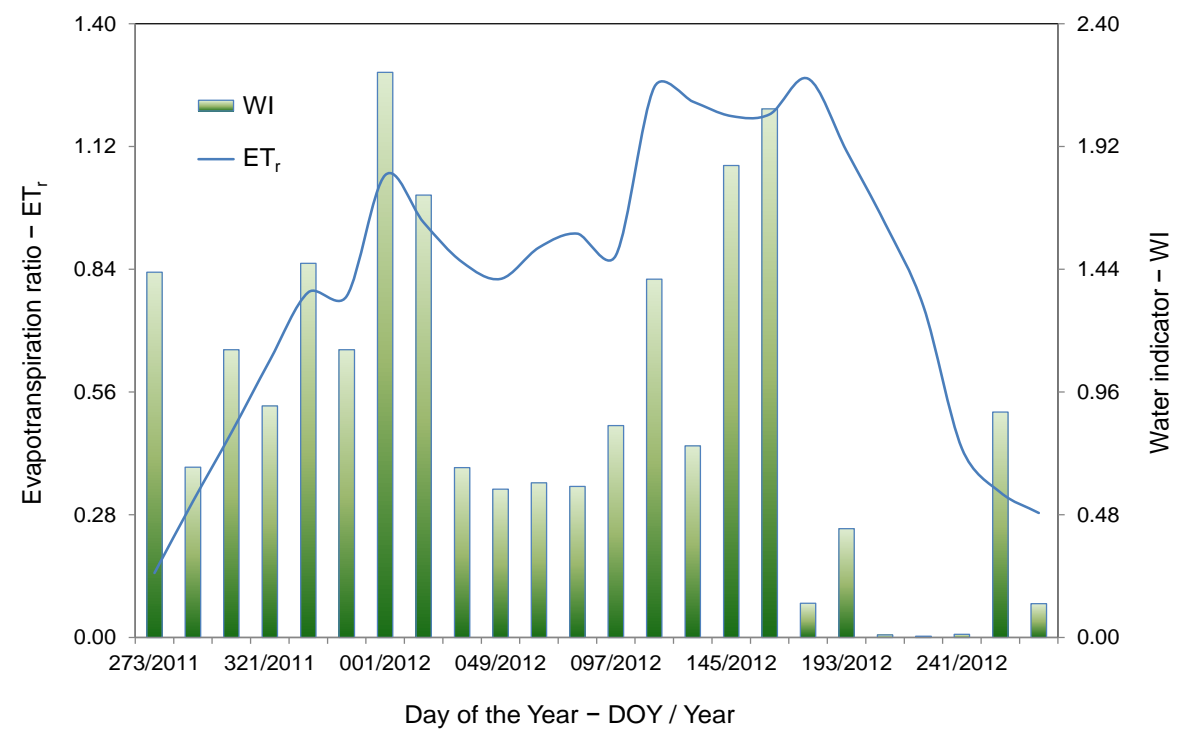

FIG. 5 SOIL MOISTURE INDICATORS. ETr: RATIO OF ACTUAL (ET) TO REFERENCE (ETo) EVAPOTRANSPIRATION; WI: RATIO OF PRECIPITATION (P) TO ET

Declines in ET $\mathrm{r}$ values occurred between DOY 017 and 113 of 2012, inside the Phase 3, but not dropping below 0.80 . The maximums, above 1.20 at the end of this phase, were observed from the middle April to the middle May in the year 2012. ETr in rainfed crops can be used to characterize the moisture status in the root zones [38], while under good irrigation conditions it is considered as the crop coefficient $\left(\mathrm{K}_{\mathrm{c}}\right)$, being used for irrigation management [28] [39].

Sugarcane $\mathrm{K}_{\mathrm{c}}$ values, fully covering the soil, were reported to be between 1.1 and 1.5, depending on the weather conditions [36], being typically around 1.25 [28] [39] as it was verifyied in the Phase 3 of the current study. These similarities again bring confidence for the SAFER application to MODIS images. Although the ETr curve pictured in Fig. 5 being for rainfed sugarcane crop, the maximum values corresponded to $\mathrm{K}_{\mathrm{c}}$ under optimum irrigation conditions, except for the period between DOY 017 to 113 in the year 2012.

Throughout the trend of the WI indicator, one can see that its values followed those for ETr. However, the decline on ETr was not as deep as it was on WI during Phase 3. This fact means that even with P reduction during this phase, the soil moisture still kept the rainfed sugarcane development. In average, the ET rates accounted for $80 \%$ of those for the reference grass $\left(\mathrm{K}_{\mathrm{c}}=0.80\right)$; and rainfalls, in general, met the crop water requirements satisfactorily, with P representing $90 \%$ of ET (WI $=0.90)$. However, supplementary irrigation should be economically feasible during Phase 3, wherever there is water available for this practice, especially by using efficient methods such as drip irrigation, which could improve the sugarcane WP.

\section{Biomass Production}

Fig. 6 shows the spatial distribution of the sugarcane BIO daily averages, for the 16-day period MODIS images, from September 2011 to October 2012, in the growing areas of the São Paulo state, Brazil.

As there is a relationship between ET and BIO [15], the periods with the highest $\mathrm{BIO}$ are the same as those for ET, inside the Phase 3, with BIO pixel values above $200 \mathrm{~kg} \mathrm{ha}^{-1}$ day-1$^{-1}$. The lowest ones took place at the start of the Phase 1, from DOY 273 to 305 of 2011, and at the end of the Phase 4, from DOY 257 to 281 of 2012, when they were below $50 \mathrm{~kg} \mathrm{ha}^{-1}$ day $^{-1}$.

Rainfall, in general, favored BIO, providing good moisture levels in the root zone of the sugarcane crop, in the whole generalized GC, except at the end of Phase 4, when low rain amounts are favorable for juice quality for the rainfed canes. The short period of lowering P, during Phase 3, even with an increased atmospheric demand - as observed by the ETo values, did not significantly reduced BIO (see Figs. 3 and 6). However, as in the case of ET, a decline in the BIO values was observed at the transition of Phase 3 to Phase 4 , what is considered common to 
happen in sugarcane crop [23].

Althoug high RG levels increasing the atmospheric demand, i.e high ETo values, in Phase 4, the low rainfall amounts did not contribut to raize BIO values (see Figs. 3 and 5).

The variation of the BIO SD values followed those for ET, with the lowest (22 $\left.\mathrm{kg} \mathrm{ha}^{-1} \mathrm{day}^{-1}\right)$ and the highest $\left(88 \mathrm{~kg} \mathrm{ha}^{-1}\right.$ day $\left.^{-1}\right)$ in the Phases 1 and 4, respectively.

Under irrigation conditions, Oliver and Singels [40] reported strong BIO declines, when water application was reduced by $50 \%$, depending on the sugarcane variety. However, Andrade et al. [27] affirmed that the soil moisture effects on BIO vary also according to the planting and harvesting dates. In South Africa, Donaldson et al. [24] reported seasonal variations affecting BIO in a number of sugarcane cultivars, being the ranges between 90 and $184 \mathrm{~kg} \mathrm{ha}^{-1}$ day $^{-1}$.

In a study with irrigated sugarcane crop, in the Minas Gerais, Brazil, Andrade et al. [27] obtained average BIO values within the range between 100 and $160 \mathrm{~kg} \mathrm{ha}^{-1} \mathrm{day}^{-1}$, similar to those from our study, during several crop periods. BIO increases can be reached by improvements on the natural resources use, mainly throughout RG interception and water management [36].

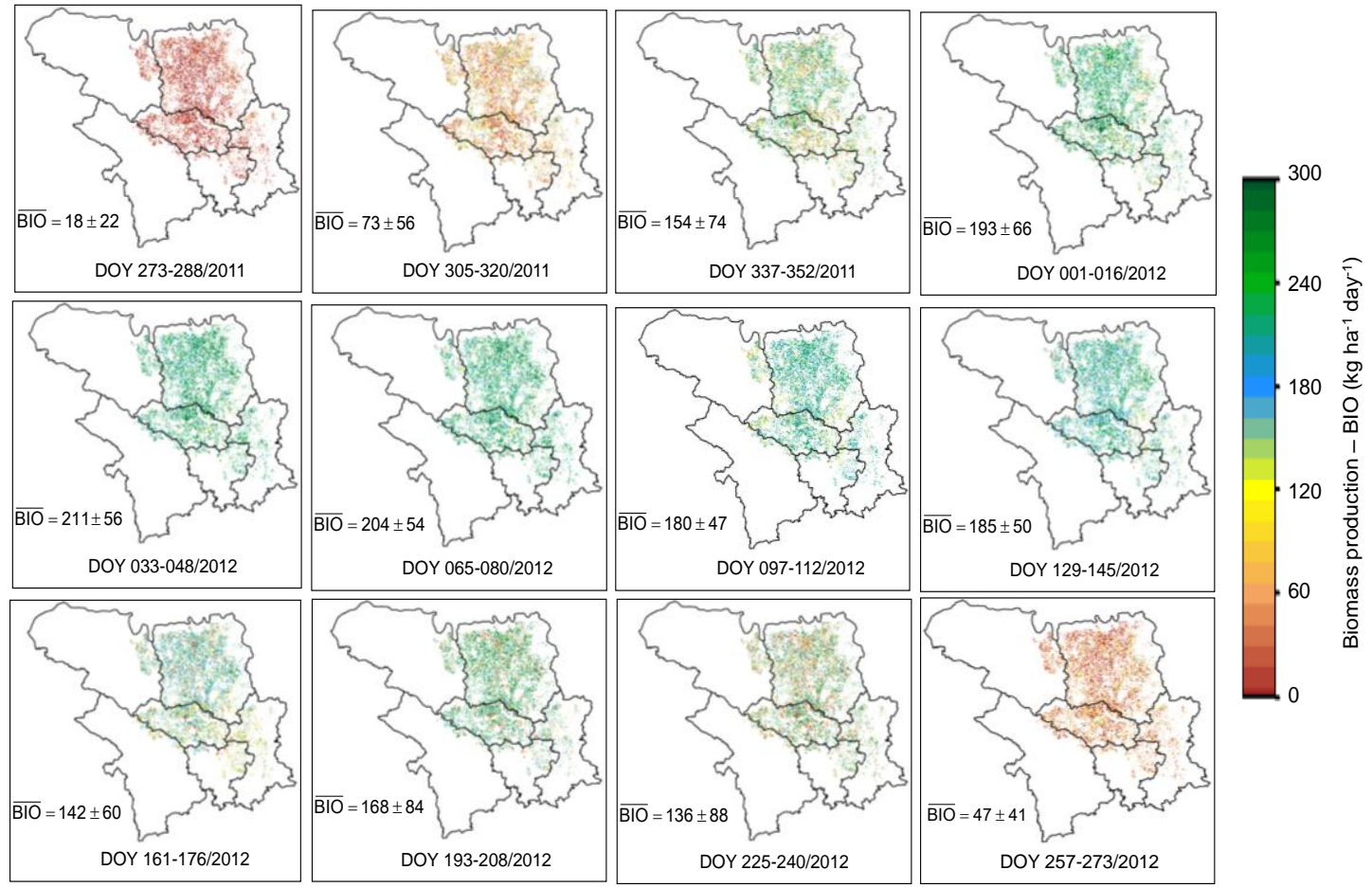

FIG. 6 SPATIAL DISTRIBUTION FOR THE 16-DAY AVERAGE VALUES OF THE SUGARCANE BIOMASS PRODUCTION (BIO)

\section{Water Productivity}

Fig. 7 shows the pixel averages and standard deviations (SD) of the sugarcane WP, for the 16-day period MODIS images, and a generalized GC from September 2011 to October 2012 in the growing areas of the São Paulo state, Brazil.

Sugarcane WP values started with an average of $2.5 \mathrm{~kg} \mathrm{~m}^{-3}$ in Phase 1 . They increased to around $4.4 \mathrm{~kg} \mathrm{~m}^{-3} \mathrm{during}$ Phase 2, going to a mean value of $5.4 \mathrm{~kg} \mathrm{~m}^{-3}$ in Phase 3 to fall again to a an average of $3.7 \mathrm{~kg} \mathrm{~m}^{-3}$ in Phase 4 . For the entire generalized GC, the mean value was $4.4 \mathrm{~kg} \mathrm{~m}^{-3}$. The short rainfall reductions during Phase 3 did not dropped WP values bellow $4.5 \mathrm{~kg} \mathrm{~m}^{-3}$. The lowest SD happened during the rainy period, at the start of the Phase 3 , while the highest ones were toward the end of this phase to the start of Phase 4.

Cabral et al. [17], through eddy covariance measurements found similar sugarcane WP for two growing cycles in the São Paulo state, Brazil, averaging $4.2 \mathrm{~kg} \mathrm{~m}^{-3}$. Chooyok et al. [5] reported sugarcane WP of 5.8 and $6.5 \mathrm{~kg} \mathrm{~m}^{-3} \mathrm{for}$ two distinct regions of Thailand, concluding that these values depend on climate, soil, and planting date. Eksteen 
et al. [36] in South Africa found WP values between 5.8 and $7.8 \mathrm{~kg} \mathrm{~m}^{-3}$ for different sugarcane varieties and irrigation regimes. However, according to Chooyok et al. [5], the global sugarcane WP average is around $4.8 \mathrm{~kg} \mathrm{~m}^{-3}$, matching well with the mean pixel values of our study, when considering the generalized GC. These agreements provide confidence to the models used for ET and BIO with MODIS images and without the thermal band, in the sugarcane growing areas of São Paulo state, Brazil.

Considering the importance of sugarcane crop, for sugar and alcohol production, and also for generating renewable energy, the high WP values under rainfed conditions, with sustainable crop management, can compensate the negative effects of land use changes caused by its fast expansion in the Southeast Brazil.

The monitoring of the sugarcane WP dynamics on large scale in the main growing regions of Brazil is very important because of the actual scenario of water competitions with other sectors, as consequences of both climate and land use changes.

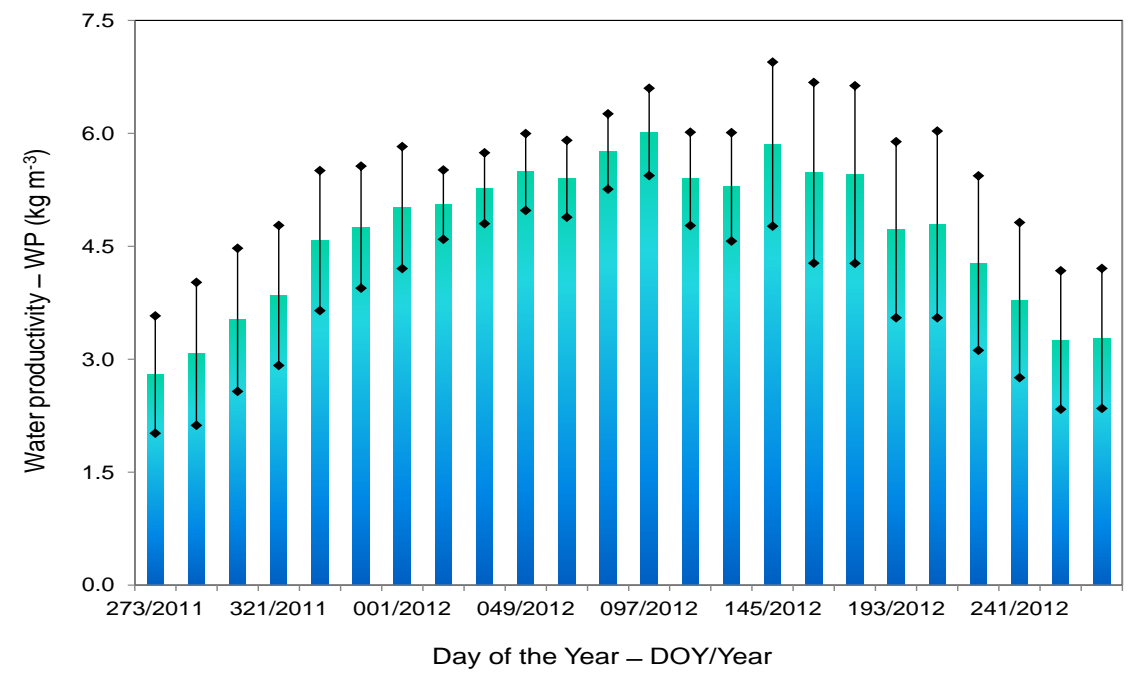

FIG. 7 DAILY AVERAGES FOR SUGARCANE WATER PRODUCTIVITY (WP) TOGETHER WITH THE STANDARD DEVIATIONS (SD)

\section{Conclusions}

The joint use of remote sensing parameters obtained from the MODIS red and near-infrared bands, together with weather stations, allowed the water productivity assessments for rainfed sugarcane in the growing regions of the São Paulo state, Brazil. The combination of the SAFER algorithm with the Monteith's radiation efficiency model is proved to be very useful for determining evapotranspiration and biomass production, regardless of the thermal band absence in the orbital sensors.

Through water indicators, the benefits from supplementary irrigation were noticed in the transition sugarcane phases from tillering to grand growth, even though the results have demonstrated that rainfall water use is highly efficient under the environmental conditions of the study growing regions.

The models successfully tested may be implemented in order to monitor the effects of the sugarcane expansion on the large-scale water balance and the adverse impacts from climate and land use changes. The limitations of the low $1 \mathrm{~km}$ spatial resolution from the MODIS thermal band were eliminated, through the residual method for estimating the surface temperature from the radiation balance. This technique allows the water balance indicators acquirements at a $250 \mathrm{~m}$ spatial resolution in the mixed sugarcane ecosystem.

\section{ACKNOWLEDGMENT}

To the Brazilian institutes: National Council for Scientific and Technological Development (CNPq), for the support to water productivity projects; National Institute for Space Research (INPE), for making available the crop land mask; and National Institute of Meteorology (INMET), for providing weather data. 


\section{REFERENCES}

[1] Mello, C.O., and Esperancini M.S.T. “Análise econômica da eficiência da produção de cana-de-açúcar de fornecedores do Estado do Paraná." Revista Energia na Agricultura 27 (2012): 48-60.

[2] Rudorf, B.F.T., et al. "Studies on the rapid expansion of sugarcane for ethanol production in São Paulo State (Brazil) using Landsat Data." Remote Sensing 2 (2010): 1057-1076.

[3] Scharlemann, J.P., and Laurance, W.F. "How Green Are Biofuels?” Science 319 (2008): 43-44.

[4] Waclawovsky, A.J., Sato, P.M., Lembke, C.G., Moore, P.H., and Souza, G.M. “Sugarcane for bioenergy production: an assessment of yield and regulation of sucrose content." Plant Biotechnology Journal 8 (2010): 1-14.

[5] Chooyok, P., Pumijumnog, N., and Ussawarujikulchai, A.T. "The water footprint assessment of ethanol production from molasses in Kanchanaburi and Supanburi province of Thailand." Procedia APCBEE 5 (2013): 283-287.

[6] Beringer, T., Lucht, W., and Schaphoff, S. "Bioenergy production potential of global biomass plantations under environmental and agricultural constraints." GCB Bioenergy 3 (2011): 299-312.

[7] Cerri, C.C.; Galdos, M.V., Maia, S.M.F., Bernoux, M., Feigl, B.J., Powlson, D., and Cerri, C.E.P. "Effect of sugarcane harvesting systems on soil carbon stocks in Brazil: an examination of existing data." European Journal of Soil Science 62 (2011): 23-28.

[8] Anderson-Teixeira, K.J. et al. "Climate-regulation services of natural and agricultural ecoregions of the Americas." Nature Climate Change 2 (2012): 177-181.

[9] Gunkel, G. et al. "Sugar cane industry as a source of water pollution-case study on the situation in Ipojuca River, Pernambuco, Brazil." Water, Air \& Soil Pollution 180 (2007): 261-269.

[10] Silva, T.G.F. da et al. "Demanda hídrica e eficiência do uso da água da cana-de-açúcar irrigada no semiárido brasileiro." Revista Brasileira de Engenharia Agrícola e Ambienal 15 (2011): 1257-1265.

[11] Cabral, O.M.R. et al. “Water use in a sugar-cane plantation.” GCB Bioenergy 4 (2012): 555-565.

[12] Wu, C., Munger, J.W., Niu, Z., and Kuanga, D. “Comparison of multiple models for estimating gross primary production using MODIS and eddy covariance data in Havard Forest.” Remote Sensing of Environment 114 (2010), $2925-2939$.

[13] De Silva, A.L.C., and De Costa, W.A.J.M. “Growth and radiation use efficiency of sugarcane under irrigated and rain-fed conditions in Sri Lanka." Sugar Tech 14 (2012): 247-254.

[14] Adak, T., Kumar, G., Chakravarty, N.V.K., Katiyar, RK, and Deshmukh, P.S. “Biomass and biomass water use efficiency in oilseed crop (Brassica Jnceae L.) under semi- arid microenvironments." Biomass and Bioenergy 51 (2013): 154-162.

[15] Teixeira, A.H. de C.; Scherer-Warren, M.; Hernandez, F.B.T.; Andrade, R.G., and Leivas, J.F. “Large-Scale Water Productivity Assessments with MODIS Images in a Changing Semi-Arid Environment: A Brazilian Case Study." Remote Sensing 11 (2013): 5783-5804.

[16] Teixeira, A.H. de C., Hernandez, F.B.T., Lopes, H.L., Scherer-Warren, M., and Bassoi, L.H. “A Comparative Study of Techniques for Modeling the Spatiotemporal Distribution of Heat and Moisture Fluxes in Different Agroecosystems in Brazil." In Remote Sensing of Energy Fluxes and Soil Moisture Content, edited by George P. Petropoulos, 169-191. CRC Group, Taylor and Francis, Boca Raton, Florida, 2014.

[17] Cabral, O.M.R. et al. "Fluxes of CO2 above a sugarcane plantation in Brazil." Agricultural and Forest Meteorology 182-183 (2013): 54-56.

[18] Claverie, M. et al. "Maize and sunflower biomass estimation in southwest France using spatial and temporal resolution remote sensing data." Remote Sensing of Environment 124 (2012), 884-857.

[19] Teixeira, A.H. de C. et al. "Water balance indicators from MODIS images and agrometeorological data in Minas Gerais state, Brazil." Proceedings of SPIE 9637 (2015), 963700-1-14.

[20] Teixeira, A.H. de C., Bastiaanssen, W.G.M., Ahmad, M-ud-D, Bos, M.G., and Moura, M.S.B. “Analysis of energy fluxes and vegetation-atmosphere parameters in irrigated and natural ecosystems of semi-arid Brazil." Journal of Hydrology 362 (2008): 110-127. 
[21] Teixeira A.H. de C. "Determining regional actual evapotranspiration of irrigated and natural vegetation in the São Francisco river basin (Brazil) using remote sensing and Penman-Monteith equation. “ Remote Sensing 2 (2010): 1287-1319.

[22] Monteith, J.L “Solar radiation and productivity in tropical ecosystems.” Journal of Applied Ecology 9 (1972): 747-766.

[23] van Heerden, P.D.R., Donaldson, R.A., Watt, D.A., and Singels, A. “Biomass accumulation in sugarcane: unravelling the factors underpinning reduced growth phenomena." Journal of Experimental Botany 61 (2010): 2877-2887.

[24] Donaldson, R.A., Redshaw, K.A., Rhodes, R., and van Anterpen, R. "Season effects on productivity of some commercial South African sugarcane cultivars, I: Biomass and radiation use efficiency." Proceedings of the South Africa Sugar Technology Association 81 (2008): 517-527.

[25] Shi, X. et al. "Using spatial information technologies to select sites for biomass power plants: A case study in Guangdong, China." Biomass and Bioenergy 32 (2008): 35-43.

[26] Teixeira, A. H. de C. et al. Coupling MODIS images and agrometeorological data for agricultural water productivity analyses in the Mato Grosso state, Brazil. Proceedings of SPIE 9239 (2014): 92390W-1-92390W-14.

[27] Andrade, R.G., Sediyama, G., Soares, V.P., Gleriani, R.G., and Menezes, S.J.M.C. “Estimativa da produtividade da cana-deaçúcar utilizando o SEBAL e imagens Landsat." Revista Brasileira de Meteorologia 29 (2014): 433-442.

[28] Allen, R.G., Pereira, L.S., Raes, D., and Smith, M.. “Crop evapotranspiration. Guidelines for computing crop water requirements." FAO Irrigation and Drainage Paper 56, Rome, Italy, 300 pp, 1998.

[29] Cleugh, H.A., Leuning, R., Mu, Q., and Running, S.W. “Regional evaporation estimates from flux tower and MODIS satellite data." Remote Sensing of. Environment 106 (2007): 285-304.

[30] Valiente, J.A., Nunez, M., Lopez-Baeza, E., and Moreno, J.F. “Narrow-band to broad-band conversion for Meteosat visible channel and broad-band albedo using both AVHRR-1 and -2 channels." International Journal of Remote Sensing 16 (1995): 1147-1166.

[31] Bastiaansssen, W.G.M., Menenti, M., Feddes, R.A., Roerink, G.J., and Holtslag, A.A.M. “A remote sensing surface energy balance algorithm for land (SEBAL) 1. Formulation.” Journal of Hydrology 212-213 (1998): 198-212.

[32] Allen, R.G., Hartogensis, O., and de Bruin, H.A.R. "Long-wave radiation over alfafa during the RAPID field campaign in southern Idaho." Research Report, Kimberly, University of Idaho, Id, 2000.

[33] Bastiaanssen, W.G.M., and Ali, S. “A new crop yield forecasting model based on satellite measurements applied across the Indus Basin, Pakistan." Agriculture, Ecosysistems \& Environment 94 (2003): 32-340.

[34] Tejera, N.A.; Rodes, R., Ortega, E., Campos, R., and Lluch, C. “Comparative analysis of physiological characteristics and yield components in sugarcane cultivars." Field Crops Research 102 (2007), 64-72.

[35] Inman-Bamber, N.G., and Smith, D.M “Water relations in sugarcane and response to water deficits." Field Crops Research 92 (2005): 185-202.

[36] Eksteen, A., Singels, A., and Ngxaliwe, S. "Water relations of two contrasting sugarcane genotypes." Field Crops Research 168 (2014), 86-100.

[37] Omary, M., and Izuno, F.T. "Evaluation of sugar-cane evapotranspiration from water table data in the everglades agricultural area." Agricultural Water Management 27 (1995): 309-319.

[38] Lu, N., Chen, S., Wilske, B., Sun, G., and Chen, J. “Evapotranspiration and soil water relationships in a range of disturbed and undisturbed ecosystems in the semi-arid Inner Mongolia, China.” Journal of Plant Ecology 4 (2011): 49-60.

[39] Inman-Bamber, N.G., and McGlinchey, M.G. “Crop coefficients and water-use estimates for sugarcane based on long-term Bowen ratio energy balance measurements." Field Crops Research 83 (2003): 125-38.

[40] Oliver, F.C., and Singles, A. "Water use efficiency of irrigated sugarcane as affected by variety and row spacing." Proceedings of the South Africa Sugar Technologist Association 77 (2003), 347-351. 